\title{
PARA QUE ENSINAR CIÊNCIA NO SÉCULO XXI? - REFLEXÕES A PARTIR DA FILOSOFIA DE FEYERABEND E DO ENSINO SUBVERSIVO PARA UMA APRENDIZAGEM SIGNIFICATIVA CRÍTICA
}

FELIPE DAMASIO - (https://orcid.org/0000-0003-4539-7139)* Instituto Federal de Santa Catarina, Araranguá, SC - Brasil

LUIZ 0. Q. PEDUZZI - (https://orcid.org/0000-0002-1113-4704)* * Universidade Federal de Santa Catarina, Florianópolis, SC - Brasil

RESUMO: A sociedade contemporânea é marcada por mudanças drásticas e rápidas, e assim uma educação pautada em transmitir verdade, certezas, dicotomias, entidades isoladas vem perdendo o sentido. A escola poderá ser mais útil se preparar os alunos para não serem subjugados aos poderes dominantes presentes na sociedade em que vivemos. Em especial, a educação em ciências pode ter um papel importante nesta nova forma de ver a educação. Este trabalho relata uma pesquisa de caráter teórico e empírico que procurou explorar como as obras de Neil Postman, Paul Feyerabend e Marco Antonio Moreira podem contribuir para evidenciar como a educação científica pode ser útil no século XXI. A articulação desses referenciais para uma educação científica por meio de história da ciência tem o objetivo de formar pessoas questionadoras, flexíveis, criativas, inovadoras, tolerantes e progressistas; que segundo Postman e Moreira, são as que menos se subjugam aos poderes constituídos na sociedade contemporânea.

Palavras-chaves: Ensino subversivo; Aprendizagem significativa crítica; Paul Feyerabend; História da ciência.

WHY TEACH SCIENCE IN THE $21^{\text {ST }}$ CENTURY? - REFLECTIONS FROM FEYERABEND'S PHILOSOPHY AND SUBVERSIVE EDUCATION FOR CRITICAL MEANINGFUL LEARNING

ABSTRACT: Contemporary society is marked by drastic and rapid changes, where an education based on truth is losing its meaning. The school may be more useful if it prepares students so they will not be subjugated to the society in which we live. In particular, science education can play an important role in this new way of seeing education. This paper reports a research of theoretical and empirical nature that sought to explore how the works of Neil Postman, Paul Feyerabend and Marco Antonio
*Doutor em Educação Científica e Tecnológica (UFSC). Instituto Federal de Santa Catarina/Grupo de Estudos em

Educação e Divulgação Científicas. E-mail: < felipedamasio@ifsc.edu.br >

* Doutor em Ensino de Ciências Naturais e

Matemática pela Universidade Federal de Santa Catarina (UFSC). Departamento de Físical Programa de Pós Graduação em Educação Científica e Tecnológica. Universidade Federal de Santa Catarina E-mail:<luizpeduzzi@gmail.com> 
Moreira can contribute to how scientific education can be useful in the 21 st century. The articulation of these references to a scientific education through the history of science aims to train people who are inquisitive, flexible, creative, innovative, tolerant and progressive; which, according to Postman and Moreira, are the ones that least subjugate to contemporary society.

Keywords: Subversive education; Critical meaningful learning; Paul Feyerabend; Science history.

¿PARA QUÉ ENSEÑAR A LAS CIENCIAS EN EL SIGLO XXI? - REFLEXIONES A PARTIR DE LA FILOSOFÍA DE FEYERABEND Y DE LA ENSEÑANZA SUBVERSIVA PARA UN APRENDIZAJE SIGNIFICATIVO CRÍTICO

RESUMEN: La sociedad contemporánea está marcada por cambios drásticos y rápidos y, así, una educación comprometida a transmitir verdad, certidumbres, dicotomías y entidades aisladas ha perdido el sentido. La escuela podrá ser más útil si prepara a los alumnos para no ser sojuzgados a los poderes dominantes presentes en la sociedad en que vivimos. En especial, la educación de las ciencias puede ter un papel importante en esta nueva manera de ver la educación. Este trabajo relata una investigación de carácter teórico y empírico que buscó explorar cómo las obras de Neil Postman, Paul Feyerabend y Marco Antonio Moreira pueden contribuir para evidenciar cómo la educación científica puede ser útil en el siglo XXI. La articulación de eses referenciales para una educación científica por medio de historia de las ciencias tiene el objetivo de formar personas cuestionadoras, flexibles, creativas, innovadoras, tolerantes y progresistas; que, segundo Postman y Moreira, son las que menos se sojuzgan a los poderes constituidos en la sociedad contemporánea.

Palabras clave: Enseñanza subversiva. Aprendizaje significativo crítico. Paul Feyerabend. História de las Ciencias. 
Para que ensinar Ciência no Século XXI? - reflexões a partir da filosofia de

Feyerabend e do ensino subversivo para uma aprendizagem significativa crítica

\section{INTRODUÇÃO}

Segundo Postman e Weingartner (1978), mudanças rápidas e drásticas são características da nossa contemporaneidade. Não obstante, para Aranha (1996), as escolas não acompanham as aceleradas mudanças que aparecem na sociedade e, segundo Fronza (2016), há uma grande distância entre a vivência escola e a vivência social. Com base nessas asserções, proporcionar, por meio da educação científica, subsídios relevantes para o desenvolvimento de uma cidadania mais consciente e atuante, consiste em um grande desafio contemporâneo.

Postman e Weingartner (1978) sugerem o que chamam de uma nova educação, que implica uma nova escola, diferente da atual que, segundo a visão dos autores, forma pessoas dependentes de autoridade não ensinando muita coisa proveitosa para a sobrevivência na sociedade contemporânea. A nova escola seria mais profícua se fosse subversiva - tendo como função subverter atitudes, crenças e pressupostos que fomentam a esterilidade - além de desenvolver, nos estudantes, atitudes de aptidão de crítica social, política e cultural. Este é o ensino subversivo de Postman e Weingartner, aquele capaz de fazer o sujeito se inserir em sua própria cultura e ao mesmo tempo situar-se longe dela.

A pesquisa relatada neste artigo visou abordar esta questão, levantando os seguintes problemas: Como a educação cientifica, dentro da perspectiva de um ensino subversivo, pode auxiliar na formação de um cidadão preparado para enfrentar uma sociedade caracterizada por mudanças rápidas e drásticas? Que aspectos históricos, filosóficos e conceituais devem constar em uma situação de educação cientifica dirigida a professores em formação para que eles fomentem um ambiente na educação científica na qual a aprendizagem significativa crítica possa ser construida?

O delineamento da pesquisa pautou-se nos cuidados e recomendações de Moreira (2004, 2009). Segundo o autor, é preciso evitar fragilidades que marcam muitos trabalhos em educação científica e tecnológica. Duas destas debilidades ganham destaque: (1) autores que relegam o conteúdo científico a um nível bem inferior em suas pesquisas e (2) trabalhos sem referenciais teórico, epistemológico e metodológico adequados e coerentes - em particular, um grande número de estudos sem marco teórico ou com um suposto aporte que não se articula com o objeto estudado. As preocupações de Moreira parecem ser ainda mais relevantes quando se percebe que a comunidade, ou um recorte dela, tem apresentado as deficiências apontadas por ele. Assim, buscou-se estruturar os fundamentos da pesquisa à luz de referenciais compatíveis com os seus objetivos, articulando-se o aporte epistemológico com a educação científica e mostrando sua coerência e complementaridade com os referenciais teórico e metodológico.

Segundo Pena (2004), apesar de grandes avanços na pesquisa em educação científica no Brasil, elas ainda têm pouco ou nenhum impacto em sala de aula. Um ponto, que reforça a assertiva de Pena, é a constatação de que muitos trabalhos oriundos da pesquisa em educação científica são teóricos, propostas sem componente empírico que impliquem ações diretamente em sala de aula. Para tentar superar esta barreira e chegar às escolas, a pesquisa relatada neste artigo objetivou levar seu desenvolvimento teórico para a sala de aula, por meio de sua implementação em cursos na formação inicial e continuada de professores. 
A pesquisa tem três eixos básicos: o teórico educacional (Teoria da Aprendizagem Significativa Crítica), o epistemológico (relativismo de Paul Feyerabend) e o metodológico (Unidades de Ensino Potencialmente Significativas). O mapa conceitual apresentado na Figura 1 procura dar uma visão geral do estudo desenvolvido. Conforme Moreira (2013), mapas conceituais são úteis como recurso para apresentação de um determinado tópico. Sendo representações externas que mostram uma organização interna, é necessário que eles sejam explicados pelos proponentes. O mapa explicita os objetivos específicos da pesquisa, sendo cada um deles alvo de um artigo particular. Os artigos podem ser lidos independentemente, mas, em conjunto, conferem unidade à pesquisa, que teve como objetivo geral articular um aporte epistemológico com o ensino subversivo para uma educação científica de e sobre ciência.

O Artigo 1 (DAMASIO e PEDUZZI, 2017a) tratou de produzir uma revisão bibliográfica, a partir de programas de pós-graduação, para levantar os motivos que pesquisadores em formação têm alegado para justificar o ensino de história e filosofia da ciência na educação científica, além de procurar identificar a existência e apropriação dos aportes epistemológico e educacional. A revisão alicerçou boa parte da investigação, pois mostrou diretrizes para seguir a fim de evitar debilidades recorrentes na pesquisa em educação científica.

Figura 1. Mapa conceitual mostrando a unidade da pesquisa

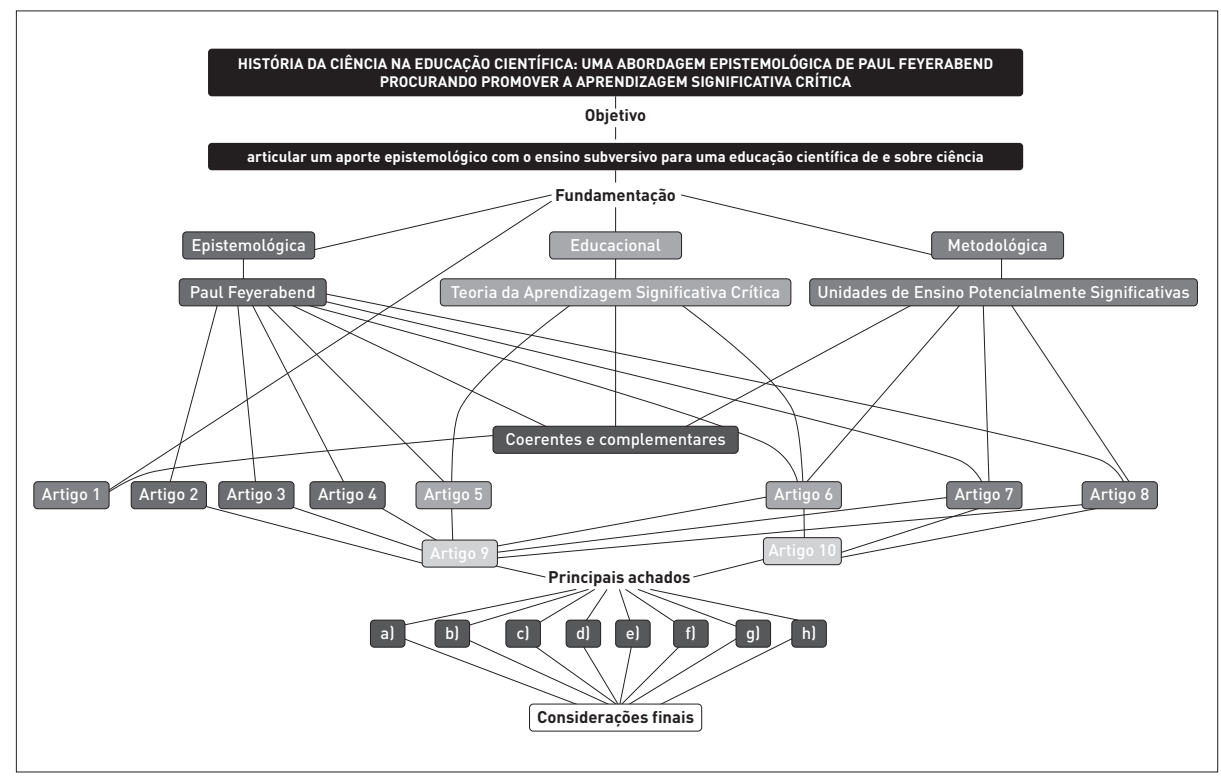

Fonte: Os autores.

A partir do eixo epistemológico, procurou-se por interfaces da filosofia da ciência de Feyerabend com a educação científica e deste estudo produziram-se mais três artigos. O Artigo 2 (DAMASIO e PEDUZZI, 2015a) analisou questões polêmicas acerca da epistemologia de Paul Feyerabend e como tal discussão pode ter impacto na formação de professores. O Artigo 3 (DAMASIO e PEDUZZI, 
2017b) investigou a (im)pertinência da alcunha atribuída a Paul Feyerabend de pior inimigo da ciência e a fundamentação das críticas à epistemologia de Feyerabend, feitas por pesquisadores da área de educação científica. O Artigo 4 (DAMASIO e PEDUZZI, 2015b) examinou a crítica dentro da moderna filosofia da ciência da defesa da relação intrínseca entre o empreendimento científico e o uso da razão, inclusive traçando paralelos entre o pensamento racionalista e o de defensores de uma religião. Partindo destas reflexões, o artigo indica a possibilidade de desmistificação da ciência, aproximando-a de estudantes que não demonstram, em princípio, predisposição em aprendê-la.

O Artigo 5 (DAMASIO e PEDUZZI, 2015c) procurou explorar a coerência e complementaridade entre a epistemologia de Feyerabend e a Teoria da Aprendizagem Significativa Crítica. Esta construção se mostrou necessária, de forma a evitar as debilidades apontadas na revisão bibliográfica, de ausência de articulação entre os aportes epistemológico e educacional, isso quando esses aportes existem. O Artigo 6 (DAMASIO e PEDUZZI, 2016a) é uma sequência natural da pesquisa, que desenvolveu alternativas para uma formação inicial de professores, procurando viabilizar uma docência para um ensino subversivo visando uma aprendizagem significativa crítica.

As propostas levantadas no sexto artigo utilizam como recurso as discussões de episódios históricos da ciência sob o viés relativista, como parte de Unidades de Ensino Potencialmente Significativas (UEPS). No entanto, tais propostas necessitavam de material instrucional, o que foi desenvolvido nos próximos dois artigos.

O Artigo 7 (DAMASIO e PEDUZZI, 2016b) se constitui em um texto sobre os dois julgamentos de Galileu a partir de uma interpretação de que no primeiro julgamento a lógica estava ao lado da Igreja e que, no segundo, ela poupou Galileu de acusações muito mais graves do que a sua defesa do sistema copernicano. Já o Artigo 8 (DAMASIO e PEDUZZI, 2017c) buscou elaborar um texto (em consonância com os referenciais teóricos da pesquisa) sobre a insustentabilidade da versão empírico-indutivista que associa a gênese da teoria da relatividade restrita ao resultado negativo do experimento de Michelson-Morley.

Uma vez que a pesquisa já havia desenvolvido todos os objetivos teóricos, os dois próximos artigos da investigação procuraram levar tal construção para as salas de aula da formação de professores. O Artigo 9 (DAMASIO e PEDUZZI, 2017d) pretendeu implementar e avaliar a experiência proposta para a formação continuada de professores e, o Artigo 10, por sua vez, na formação inicial de professores. Ambos os artigos foram estudos de casos do tipo etnográfico, e utilizaram a Teoria Fundamentada em sua análise. Dos estudos de caso emergiram oito achados que são as contribuições principais da pesquisa. No entanto, destes achados surgiram muitos problemas que permanecem em aberto para a área da educação científica, e uma solução para eles certamente demandará muitos anos de pesquisa pela comunidade.

Por fim, nas considerações finais da pesquisa, apresenta-se uma educação científica inserida dentro de uma escola que pode ser útil para a sociedade contemporânea. Tais reflexões são vislumbradas a partir das discussões e avanços da investigação. A seguir apresentam-se os principais resultados de cada etapa/ artigo da pesquisa, bem como de que forma elas se articulam no âmbito dos objetivos e da unidade do trabalho. 


\section{REVISÃO DA LITERATURA}

Em função dos três eixos da pesquisa - epistemológico, educacional e metodológico - julgou-se pertinente fazer uma revisão bibliográfica da literatura (Artigo 1) a fim de mapear como tais referenciais são tratados por pesquisadores na área da educação científica que fazem uma abordagem didática de história e filosofia da ciência. Para isso, fez-se um recorte na literatura analisando-se o período compreendido entre 2005 e 2014. Ao todo, foram investigados 41 trabalhos, sendo oito teses e trinta e três dissertações.

O estudo teve como objetivos: identificar as referências epistemológicas e educacionais declaradas pelos autores, investigar as razões apresentadas pelos autores para o uso didático da história e filosofia da ciência e se, e como, os autores articulam os referenciais adotados com a abordagem na educação científica de história e filosofia da ciência.

A análise mostrou que, no que se refere ao referencial educacional, 63\% não declararam seu embasamento. Em relação ao aporte epistemológico, 34\% também não se referiram a sua fundamentação, e dentre os que fizeram, grande parte optou por Thomas Kuhn e uma base epistemológica que se opusesse ao indutivismo. As principais justificativas para defender o uso didático da história da ciência foram: possibilidade de discutir a natureza da ciência e a de tornar o aluno crítico. Por fim, apenas $27 \%$ dos trabalhos apresentaram uma articulação entre os aportes educacionais e epistemológicos declarados.

Os resultados encontrados trouxeram reflexões para a pesquisa como um todo, identificando, por exemplo, que tanto Feyerabend como Moreira-Postman são muito pouco abordados no recorte feito pela revisão. Também apontou que as debilidades elencadas por Moreira (2004; 2009) se fazem presentes em trabalhos de pesquisa em educação científica. Ainda, outro ponto importante é que as justificativas mais citadas para o uso didático de história da ciência carecem de um referencial educacional e epistemológico bem fundamentado, pois é preciso deixar claro o que se entende por aluno crítico e natureza da ciência ao fazer tais justificativas.

Logo, a revisão bibliográfica reforçou pressupostos, tais como a necessidade de pavimentar de maneira sólida o entendimento acerca da ciência e sua natureza por meio do desenvolvimento do eixo epistemológico da pesquisa; evitar as debilidades na investigação em educação científica ainda presentes em trabalhos de pós-graduação por meio de fazer apontamentos sobre a coerência entre os referenciais adotados e; por fim, justificar que tipo de educação científica se defende como útil para a sociedade contemporânea desenvolvendo o eixo educacional e metodológico e levando-o para a formação de professores.

\section{EIXO EPISTEMOLÓGICO}

Ao procurar analisar o referencial epistemológico pôde-se perceber que existiam muitas possíveis interfaces entre a epistemologia de Feyerabend e a educação científica. Apesar de a educação não ter sido o foco da atenção do epistemólogo, ele teceu inúmeras críticas à educação científica tradicional que, 
em sua visão, simplifica a ciência e congela grandes porções de seu processo histórico (FEYERABEND, 2007). Ao se explorar três possíveis áreas de interação entre as contribuições de Feyerabend na educação científica, construiuse o eixo epistemológico da pesquisa: esclarecer questões polêmicas da filosofia da ciência de Feyerabend, tecer considerações sobre sua alcunha de "pior inimigo da ciência" e explorar seus argumentos de que a ciência racionalista se aproxima de uma abordagem secular de religião.

A primeira produziu o Artigo 2 que explorou o fato de que críticas à epistemologia de Feyerabend por pesquisadores da área de educação científica são infundadas. Ao se aprofundar nestas críticas, pode-se perceber que, com frequência, elas são oriundas de interpretações equivocadas da filosofia do autor, sendo Feyerabend criticado pelo que ele, na verdade, não defendia. Termos e expressões como anarquismo epistemológico, irracionalidade, controle da ciência e tudo vale são usualmente criticados com um entendimento de que eles são caóticos e insustentáveis. Então, esclareceu-se que o anarquismo epistemológico não leva ao caos na ciência, que a tese central da epistemologia de Feyerabend não é o vale tudo - princípio que ele jocosamente propôs como uma piada ao anseio racionalista por princípios universais - que a defesa da irracionalidade na ciência não descaracteriza o empreendimento científico e de que o relativismo consegue explicar o progresso da ciência, ao contrário do que afirmam muitos críticos.

Perscrutando a conexão destas questões com a educação científica, dentro do âmbito da formação inicial e continuada de professores, o artigo procurou evidenciar como esse assunto pode ser útil tanto para a desconstrução de certas imagens equivocadas sobre a natureza da ciência, como para gerar cidadãos mais críticos e em maior sintonia com conceitos da moderna filosofia da ciência. A intenção desta etapa da pesquisa não foi diminuir a rejeição a Feyerabend na educação científica, tampouco na investigação em ensino de ciências, mas evitar que as críticas à epistemologia de Feyerabend sejam uma caricatura repassada por interpretações equivocadas de sua filosofia da ciência.

A seguir, abordou-se outro ponto polêmico acerca da obra de Feyerabend e sua interface com a educação científica. Muitos artigos, ao tecerem críticas à epistemologia de Feyerabend, fazem alusão à alcunha de "pior inimigo da ciência". Então, investigou-se a origem de tal alcunha, concluindo-se que ela foi popularizada por autores de um artigo publicado na revista Nature em 1987 (THEOCHARIS e PSIMOPOULOS, 1987). Em sequência, o Artigo 3 averiguou quais os motivos alegados pelos autores para aferir a Feyerabend tal alcunha, e que tais críticas eram oriundas de uma defesa do monismo metodológico e da unidade da ciência. Também, pelas críticas ao entendimento que as observações estão embebidas de teorias, além de tecerem censura a flexibilidade do conceito de verdade científica e por sua defesa rigorosa de um método científico, associado à verificação experimental. Além de considerar que, a partir de uma adequação empírica as teorias científicas devem ser entendidas verdadeiras.

$\mathrm{Na}$ análise das críticas que levaram esses autores a cunharem o termo de "pior inimigo da ciência", percebe-se que, especificamente em relação à epistemologia de Feyerabend, elas se enquadram no que o epistemólogo chamou de incompetência profissionalizada (FEYERABEND, 2011). Um exemplo é quando 
afirmam que o anarquismo epistemológico de Feyerabend levaria a um anarquismo social. No Artigo 3, procurou-se não apenas fazer os devidos contrapontos a essa ideia equivocada como também se vislumbrou muitas possíveis áreas de conexão entre esta discussão sobre a alcunha e a educação científica. Uma delas é a necessidade de o professor estar consciente de suas convicções epistemológicas, pois todo professor de ciência é também um professor de filosofia da ciência, estando ele consciente ou não (ARTHURY, 2010).

A apropriação do eixo epistemológico da pesquisa finalizou com o Artigo 4 que aborda uma afirmativa que Feyerabend dizia ser a declaração mais provocativa que se poderia fazer: dizer que a ciência é uma religião (FEYERABEND, 1998). O trabalho analisa e critica a relação intrínseca que muitos estudiosos fazem entre ciência e razão. Também, procura discutir como, de acordo com Feyerabend, muitos procedimentos que os racionalistas classificariam como irracionais, não só estão presentes na prática científica como foram fundamentais para que a ciência existisse, tal qual a conhecemos (FEYERABEND, 2010). Ainda, traz a abordagem de Feyerabend que associa a maneira de pensar de um racionalista a de um defensor fundamentalista de uma crença qualquer. Como, por exemplo, quando o racionalista afirma que a ciência é um padrão de excelência e seu conhecimento é mais confiável que o de outras tradições. Feyerabend identifica este argumento, que evoca que uma tradição é superior a outras, como válido tanto para os pregadores de uma religião qualquer como para a defesa da superioridade científica pelos racionalistas.

A afinidade desta discussão com a educação científica mostrou-se bastante relevante ao se considerar que existe uma imagem estereotipada de que os cientistas são diferentes e buscam uma verdade absoluta. Tal imagem promove que alunos não se identifiquem com o empreendimento científico, considerandose como incapazes de gostar e praticar ciência, que seria delegada apenas a pessoas "especiais". Desconstruir esta imagem mítica de ciência, mostrando sua pluralidade e humanidade, pode criar laços dos estudantes com o empreendimento científico. E, principalmente, fazer com que a predisposição em aprender seja despertada condição fundamental para que uma aprendizagem significativa seja construída.

O eixo epistemológico da pesquisa permitiu ter segurança na apropriação da obra de Feyerabend e das suas possíveis interfaces com a educação científica. Ao procurar desconstruir más interpretações de sua filosofia da ciência e da sua alcunha de "pior inimigo da ciência", e também ao argumentar que, segundo o ponto de vista de Feyerabend, a ciência entendida pelos racionalistas se aproxima de uma crença religiosa, além de fazer paralelos destas discussões com a educação científica, pareceu ser bastante promissor o aporte epistemológico de Feyerabend para um ensino de ciência que possa ser útil na sociedade contemporânea. No entanto, o eixo epistemológico é apenas um dos três dentro de uma pesquisa em educação científica que não recaia nas debilidades apontadas por Moreira (2004; 2009). Logo, era preciso mostrar a coerência entre o aporte educacional e o epistemológico.

\section{EIXO EDUCACIONAL}

Para que a pesquisa tivesse fundamentos consistentes era necessário evidenciar que o ensino subversivo, a aprendizagem significativa crítica e a 
epistemologia de Feyerabend são coerentes. A primeira consideração feita foi que, segundo Postman (1994), um ensino subversivo em ciências só é possível por meio de uma abordagem que também inclua componentes históricos e filosóficos. No entanto, no Artigo 5 que descreveu esta fase da pesquisa, defende-se que nem toda abordagem de história e filosofia da ciência é necessária, ou mesmo compatível com um ensino subversivo. Ainda, visões racionalistas da ciência, ao defenderem a rigidez de conceitos como certeza e verdade, aproximam-se do que Postman e Weingartner (1978) chamaram de conceitos fora de foco. O Artigo 5, então, procurou mostrar que a epistemologia de Feyerabend não só é coerente com um ensino subversivo visando uma aprendizagem significativa crítica, como também é complementar à proposta da versão crítica da Teoria da Aprendizagem Significativa proposta por Moreira (2005).

Para mostrar a coerência e complementaridade dos aportes adotados pela pesquisa, aprofundou-se nas obras originais de Postman que foram a principal influência para a Teoria da Aprendizagem Significativa Crítica, percebendose um notável alinhamento entre as ideias do educador estadunidense com as do epistemólogo austríaco. A proposta de Postman para uma escola útil na sociedade contemporânea é aquela que subverte crenças, atitudes e pressupostos. Já a escolarização oriunda das ideias de Feyerabend propõe uma educação para uma sociedade livre, em que a educação geral prepare os cidadãos para escolher entre padrões, podendo assim, cada um, achar seu caminho em uma sociedade que contém grupos comprometidos com vários princípios. Mas sem, no entanto, subjugar-se de modo a se conformar com os padrões particulares.

Postman, Moreira e Feyerabend defendem formar pessoas que tenham consciência que suas ideias mais queridas podem não ser tão sólidas, além de entenderem que outros pontos de vista podem ser proveitosos. $\mathrm{Na}$ visão destes autores, uma escola útil na contemporaneidade é aquela na qual os estudantes não devem se subjugar de forma a se conformarem com padrões particulares. O Artigo 5 faz uma construção da coerência de todos os princípios da Teoria da Aprendizagem Significativa Crítica com a epistemologia de Feyerabend e conclui, ao final, que a visão relativista de Feyerabend se apresenta como alternativa epistemológica para criar um ambiente em que se possa construir uma aprendizagem significativa crítica, ao contrário das visões racionalistas de ciência.

Esta fase da pesquisa, ainda, além de mostrar a coerência entre os aportes contribuiu para evidenciar que a epistemologia de Feyerabend é complementar à Teoria da Aprendizagem Significativa Crítica. Tal complementaridade preenche, ao menos parcialmente, a lacuna da teoria que o próprio autor reconhece: sem um currículo, os princípios da aprendizagem significativa crítica não podem ser postos em prática. Logo, procurou-se mostrar que uma abordagem de história da ciência, sob o viés relativista de Feyerabend, pode oferecer um currículo para a construção de uma aprendizagem significativa crítica na escola por meio de um ensino subversivo.

Toda esta construção da articulação, entre os aportes educacional e epistemológico, foi fundamental para o estudo como um todo. $\mathrm{Na}$ sequência da pesquisa foi preciso construir a parte metodológica, levando-a para a formação de professores e, ainda, garantir que o eixo metodológico fosse coerente com os 
outros eixos do estudo. Para tanto, optou-se pela metodologia das Unidades de Ensino Potencialmente Significativas (UEPS), propostas por Moreira (2011), que foram planejadas dentro da perspectiva da Teoria da Aprendizagem Significativa Crítica, e, portanto, coerente com os eixos educacional e epistemológico. Neste ponto da pesquisa, era preciso fazer uma proposta concreta de como levar um ensino subversivo visando uma aprendizagem significativa crítica para a formação de professores. Além de produzir todo o material instrucional necessário e, ainda, propor maneiras pelas quais a proposta chegasse efetivamente à sala de aula.

\section{EIXO METODOLÓGICO}

O Artigo 6 apresentou a proposta para um ensino subversivo visando uma aprendizagem significativa crítica por meio de discussão de episódios históricos da ciência, para tanto, fez-se uso da metodologia das Unidades de Ensino Potencialmente Significativas e dos materiais instrucionais produzidos no decorrer da pesquisa. Tal proposta tinha dois pontos relevantes: construir possíveis estratégias para uma mudança na visão epistemológica corrente dos professores de ciência assim como viabilizar que essas alterações pudessem influenciar a sua prática docente. Nesse contexto, propôs-se uma formação de professores na qual fosse possível construir um ambiente de ensino subversivo para possibilitar uma aprendizagem significativa crítica e, ainda, explicitar como a história e filosofia da ciência são fundamentais neste contexto.

Para viabilizar tal cenário na formação de professores, foram organizados cursos planejados de acordo com UEPS, que são sequências didáticas orientadas pela Teoria da Aprendizagem Significativa. As UEPS foram usadas na pesquisa visando contribuir para alterar as opiniões problemáticas sobre o conhecimento científico, principalmente as concepções empírico-indutivistas dos docentes em formação, com a discussão de episódios históricos da ciência dentro de uma perspectiva relativística de Feyerabend. Além disto, durante o curso os próprios professores em formação construíram as suas UEPS visando levar as discussões para a educação básica. Desta forma, possibilita-se instrumentalizá-los para abordar tais questões em sua prática docente.

Todos os onze princípios da Teoria da Aprendizagem Significativa Crítica (MOREIRA, 2005) pautaram a proposta de UEPS para a formação de professores. Sempre iniciando com dinâmica de grupo para procurar levantar as concepções prévias dos professores em formação. As UEPS foram planejadas para resultar em aprendizagem significativa sobre e de ciência envolvidas nos episódios explorados. Para tanto, procura-se fomentar as duas condições que Ausubel et al. (1980) preconizam, a saber: material potencialmente significativo e predisposição para aprender.

A abordagem relativística de história e filosofia da ciência, no entanto, esbarra em uma das dificuldades apontadas por Postman (1994) para um ensino subversivo: a falta de materiais instrucionais. Para suprir esta lacuna, iniciou-se um processo de desenvolvimento de textos didáticos que abordam episódios históricos da ciência com um viés epistemologicamente relativístico. Ainda, os textos, apontam como tais ideias podem impactar a educação científica. Os episódios escolhidos para serem discutidos envolvem dois dos maiores ícones da física: Galileu Galileu e Albert Einstein. 
O primeiro deles, o Artigo 7 procura discutir, sob o viés relativístico de Feyerabend, aspectos relacionados aos julgamentos de Galileu no século XVII. Para tanto, além do aporte da própria epistemologia do autor austríaco, valeu-se dos estudos do historiador da ciência italiano Pietro Redondi (1991). O texto apresenta inicialmente o contexto dos julgamentos de Galileu, retratando brevemente o cenário da Reforma e Contrarreforma. Também traz questões relevantes, para entender os julgamentos, acerca do Concílio de Trento, principalmente em aspectos relacionados à transubstanciação da Eucaristia - que adotava o tomismo como aporte filosófico.

Em relação ao primeiro julgamento, de 1616, descreve-se o episódio como um conflito de tradições. Analisam-se as atitudes do cardeal Berllarmino (responsável pela condenação de Bruno à fogueira e pelo julgamento de Galileu em 1616). No artigo, argumenta-se que a lógica e a razão estavam ao lado da Igreja neste episódio, e não com Galileu. De acordo com este ponto de vista, após receber as denúncias contra Galileu, Berllarmino instaurou uma comissão para dar pareceres acerca da doutrina copernicana. $\mathrm{O}$ primeiro ponto do parecer dizia respeito a analise filosófica, e considerava o copernicanismo como insensato e absurdo em sua filosofia. Tal conclusão, não faz alusão alguma a argumentos teológicos. Cabe ressaltar que muitos estudiosos contemporâneos endossavam a análise da pouca sustentabilidade do sistema copernicano, como Tycho Brahe. Mesmo Galileu reconheceu, em seu Dialogo, que as vantagens do sistema copernicano não eram claras em relação a seus rivais. $\mathrm{Na}$ análise desenvolvida conclui-se que se os cientistas modernos estivessem na situação do comitê da Igreja em 1616, seus pareceres provavelmente seriam muito semelhantes aos dos especialistas convocados por Bellarmino. Ou seja, a lógica estava do lado de Berllarmino e não do lado de Galileu (DUHEM, 1963).

A abordagem do segundo julgamento de Galileu inicia com os conflitos entre ele e os jesuítas, que oferecem denúncias ao estudioso italiano que foram aceitas e culminaram no julgamento de 1633. No entanto, o teor das denúncias não se tornou público, e apenas uma comissão nomeada pelo papa (aliado e defensor de Galileu) soube de seu conteúdo. Da comissão, surgiram instruções rígidas, no sentido de que o tribunal deveria julgar Galileu por desobediência, além de determinar que o corpo de delito fosse o Dialogo. No entanto, Pietro Redondi encontrou documentos que permitem interpretar de maneira diferente este episódio. Segundo o entendimento deste renomado historiador, as acusações feitas pelos jesuítas eram muito mais graves e foram abafadas pelo papa para proteger Galileu. Os documentos, que sustentam a tese de Redondi, referem-se à denúncia como tendo corpo de delito Il Saggiatore, e a acusação era a defesa do atomismo - filosofia incompatível com o dogma da transubstanciação da Eucaristia. Neste último caso, tratava-se de heresia doutrinal, muito mais grave na época que a inquisitorial, que foi a acusação oferecida a Galileu pelo comitê instituído pelo papa.

Ao final, o artigo propõe uma UEPS com o objetivo de discutir os episódios históricos envolvendo os julgamentos de Galileu sob um viés relativista durante a educação científica, procurando fomentar um ambiente de ensino subversivo visando uma aprendizagem significativa crítica. Para tanto, como parte da diversidade de material instrucional (um dos princípios da Teoria da Aprendizagem Significativa Crítica), o artigo teve um papel fundamental. 
O segundo texto, o Artigo 8, sustenta a inconsistência da visão empíricoindutivista no surgimento da Teoria da Relatividade Restrita de Einstein, além de fazer comentários explícitos de uma análise epistemológica usando como aporte a filosofia de Feyerabend. O texto utiliza referências do próprio Einstein: seu artigo original de 1905, entrevistas, falas públicas, sua autobiografia, além de textos de divulgação de suas teorias. A questão explorada é que muitos textos, de divulgação científica e didáticos, por exemplo, colocam a proposta da relatividade restrita de Einstein como uma resposta aos resultados negativos de Michelson-Morley ao tentar detectar o éter, o que reforçaria o caráter empírico-indutivista da ciência.

Apesar de trazer um ponto de vista contrário à relevância dos experimentos de Michelson-Morley na gênese da relatividade restrita, o texto não deixa de reconhecer a pertinência do trabalho de Michelson e descreve o contexto em que estava inserido além de sua importância neste cenário. No entanto, ao analisar o artigo original de 1905, percebe-se que Einstein teve várias oportunidades de citar o experimento, caso ele tivesse sido relevante para a elaboração da sua Teoria da Relatividade Restrita, como mostra a análise de Holton (1969). Além de que, quando Einstein foi questionado a respeito por diversas vezes sempre negou tal ligação genética entre sua teoria e os resultados negativos de Michelson-Morley. Ao final, conclui-se, com a sustentação da epistemologia de Feyerabend, de que pode haver muitas maneiras de fazer ciência e contribuir com o conhecimento científico.

Com os textos que narram os dois episódios históricos à luz da epistemologia de Feyerabend, conclui-se a parte teórica da pesquisa. Nesta trajetória, desenvolveuse toda a fundamentação epistemológica, articulando-a com as fundamentações educacional e metodológica, propôs-se uma metodologia para levar a proposta à formação de professores e produziu-se material instrucional. A sequência natural foi implementar a proposta e avaliar seus impactos. Para tanto, desenvolveu-se dois estudos de casos do tipo etnográficos, um na formação inicial de professores e outro na formação continuada.

\section{ESTUDOS DE CASO}

Os estudos de caso do tipo etnográfico ocorreram durante o ano de 2016, em uma turma de formação continuada da Especialização em Educação Científica e Tecnológica (Artigo 9) e de uma de formação inicial do curso de Licenciatura em Física (Artigo 10). Ao todo, envolveu-se mais de duas dezenas de professores em formação, a maioria já atuando em sala de aula. Ambos os estudos tiveram como objetivo investigar as atitudes dos professores em formação quando inseridos no contexto de um ensino planejado para ser subversivo e visando uma aprendizagem significativa crítica. As questões pertinentes aos estudos envolveram as opiniões sobre o conhecimento científico e o processo ensino-aprendizagem dos professores em formação, bem como as formas pelas quais tais opiniões impactam no planejamento de sua prática docente na educação básica.

A opção pela pesquisa qualitativa foi por este tipo de investigação procurar entender uma realidade social particular, não almejando princípios universais (ERICKSON, 1986). Ainda, ela permite observar, participar, refletir e estudar a realidade social da formação de professores. A opção pela etnografia se justifica por 
lidar com coletivos, não indivíduos. Ela inicia com a observação in loco e tem como objetivo conduzir dados descritivos das atividades, concepções e contextos dentro de um cenário educativo (GOETZ e LECOMPTE, 1988). Com base nos dados obtidos, a partir de registro de diários de campo, coleta de documentação, grupos focais, entrevistas e outros meios; cabe ao pesquisador o processo de análise.

O estudo se valeu da Teoria Fundamentada (STRAUSS e COBIN, 2009); ela enseja o tratamento dos dados sistematicamente reunidos proporcionando a sua análise. O pesquisador, mesmo que tenha suas convicções teóricas, cria condições para que os achados surjam a partir da sua interpretação dos dados. O processo analítico percorreu a descrição detalhada de cada encontro da implementação, os materiais disponibilizados, atividades realizadas e o diário de bordo do pesquisador. A análise deste material visou investigar se houve ou não um ambiente subversivo pautado nos princípios da aprendizagem significativa crítica. Também contou com grupos focais e entrevistas individuais para saber as opiniões dos professores acerca da natureza da ciência e do processo de ensino-aprendizagem, além de averiguar possíveis e desejáveis indícios de aprendizagem significativa crítica.

Em relação à questão sobre se o curso realmente foi capaz de construir um ambiente subversivo pautado nos princípios da aprendizagem significativa crítica, a análise encontrou fortes indícios de que esses objetivos foram alcançados. O grupo focal e as entrevistas individuais trouxeram importantes dados analisados dentro de quatro variáveis de investigação: (i) necessidade de se repensar o ensino tradicional na sociedade contemporânea; (ii) a opinião acerca da aprendizagem significativa crítica; (iii) a impressão sobre a utilidade das UEPS e; (iv) sobre sua utilização.

A análise cruzada dos dados, tanto os que surgiram do cotidiano em sala de aula, como das entrevistas, bem como dos grupos focais, tornou possível identificar os principais achados da pesquisa. A partir da imensa quantidade de dados brutos nos estudos de caso realizados, eles foram recortados, organizados e categorizados. O que se procurou foi obter a essência do impacto nos professores em formação de terem contato com ambientes subversivos para uma aprendizagem significativa crítica. A partir destas atividades surgiram os principais achados dos estudos de caso do tipo etnográfico:

a) Uma proposta de ensino subversivo visando uma aprendizagem significativa crítica é possível dentro da formação continuada de professores;

b) A maior parte dos professores em formação dentro de uma proposta de ensino subversivo percebe que a escola atual com seu ensino tradicional perdeu o sentido e a utilidade na sociedade contemporânea;

c) A proposta de um ensino subversivo para uma aprendizagem significativa crítica é bem recebida por professores em formação;

d) Quando inseridos dentro de uma proposta subversiva, professores em formação constroem o entendimento de que não existe uma versão única e correta de história da ciência, que cada narrativa depende de uma filosofia da ciência que subjaz a ela; 
e) A necessidade de se utilizar história e filosofia da ciência para desconstruir os conceitos de verdades e certeza é vislumbrada positivamente por professores em formação dentro da perspectiva subversiva;

f) A metodologia dos princípios da Teoria da Aprendizagem Significativa Crítica dentro de uma Unidade de Ensino Potencialmente Significativa é bem vista pelos professores em formação e as unidades são entendidas como um possível aporte metodológico para uma educação mais coerente com a sociedade contemporânea;

g) Dentre os empecilhos para implementar um ensino subversivo vislumbrados pelos professores, um deles é metodológico: dificuldade de despertar a predisposição em aprender;

h) Outros dois empecilhos são de natureza política: falta de tempo para preparar uma unidade de ensino potencialmente significativa dentro da proposta subversiva devido à alta carga horária a que os professores de escolas públicas são submetidos e a obrigatoriedade de se cumprir uma ementa extensa.

Os achados dos estudos de caso foram importantes. Eles indicam diversos avanços visando propiciar um ensino subversivo objetivando uma aprendizagem significativa crítica. No entanto, tão importantes quanto os avanços da pesquisa foram as questões e desafios que surgiram a partir dela. Esses desafios fogem do escopo da área da educação científica, pois são de origem política e social. O principal desafio que se mostrou a partir dos achados do estudo foi o de como os professores podem se articular para exigir condições de trabalho que permitam que pratiquem sua docência de acordo com sua formação, pois mesmo que entendam que a escola útil na sociedade contemporânea é a alinhada a um ensino subversivo visando uma aprendizagem significativa crítica, questões de cunho sociais e políticas podem não permitir que os professores exerçam sua docência em conformidade com essa visão de mundo.

\section{PARA QUE ENSINAR CIÊNCIA NO SÉCULO XXI?}

Como reflexão final da pesquisa, procura-se formalizar as possíveis respostas para as questões que pautaram toda a pesquisa: Como a educação científica, dentro da perspectiva de um ensino subversivo, pode auxiliar na formação de um cidadão preparado para enfrentar uma sociedade caracterizada por mudanças rápidas e drásticas? Que aspectos históricos, filosóficos e conceituais devem constar em uma situação de educação científica dirigida a professores em formação para que eles fomentem um ambiente na educação científica onde a aprendizagem significativa crítica possa ser construida?

Neste sentido, primeiramente é importante salientar que, quando se trata de educação científica parece haver, pelo menos, dois questionamentos distintos. O primeiro é quase sempre supervalorizado; trata-se da questão da engenharia da educação, ou seja, das maneiras de ensinar ciência, dos métodos, dos equipamentos didáticos, etc. Não é preciso uma extensa revisão bibliográfica para perceber que 
grande parte dos pesquisadores da área se ocupa da questão de engenharia. $\mathrm{O}$ foco é produzir conhecimento para dizer ao professor como fazer seu trabalho, como ensinar ciência, além, é claro, do que ensinar de ciência.

Apesar da supervalorização da questão da engenharia da educação, a pesquisa aqui apresentada traz outra preocupação, que se pode chamar de questão metafísica: Para que ensinar ciência? Qual o papel do professor da área de educação científica? Deve ser um técnico que usufrui de métodos e equipamentos, ou vai mais além? A questão pode parecer inquietante, pois se questionado a outros profissionais qual o papel deles, não terão muita dificuldade para responder. Então, por que os profissionais da educação científica têm tanta dificuldade para responder a esta questão fundamental?

$\mathrm{O}$ professor que se considera um profissional exclusivamente com o papel de ensinar conteúdos parece minimizar sua função. Além disso, parece estar desconectado do atual cenário de nossa sociedade, no qual mudanças rápidas e drásticas ocorrem constantemente. $\mathrm{O}$ professor que se enxerga como um transmissor de conhecimento olha para o passado, e deve permanecer lá. O professor de ciência que enxerga como principal papel ensinar leis, equações, resoluções de problemas etc., parece nunca ter se perguntado sobre o porquê ensinar tais conteúdos, para que serve aprendê-los.

$\mathrm{Na}$ sociedade atual, apenas uma aprendizagem significativa sobre algum conhecimento específico não parece ser mais útil, e o docente que não reconhecer isso pode perder a importância e estar desconectado com o mundo em que vive. O professor profícuo para a sociedade contemporânea deve olhar para o presente e para o futuro. Neste cenário, o principal papel da escola deixa de ser o de ensinar conteúdos específicos de maneira significativa, mas sim o de ensinar conteúdos de tal maneira que gerem atitudes perante a sociedade em que vivemos, de como lidar e como não ser subjugado por ela. Em tempos de mudanças drásticas e rápidas, desconstruir a rigidez de conceitos como certeza, verdade, de dicotomias, de entidades isoladas, de causalidade simples e autoridade parece ser uma função bastante importante para a escola, e por consequência, do docente. Ou seja, como fazer parte de uma cultura, mas não ser subjugado por ela - a sociedade atual precisa que a escola fomente uma aprendizagem significativa crítica.

Neste contexto, a educação científica parece ser fundamental. Normalmente, a ciência é ensinada como um produto acabado, certo e não aberto à contestação. Muitos educadores, e pesquisadores da área de educação científica, parecem incentivar que a ciência deva mesmo ser ensinada como um padrão de excelência, essencialmente mais confiável que outras tradições. No entanto, conforme mostrou o eixo epistemológico da pesquisa, para Feyerabend, este entendimento da ciência como padrão de excelência é fruto de um mito, de que tudo que o público entende como ciência provém de uma fonte única, ou seja, é oriundo da percepção da ciência como uma unidade praticada da mesma maneira - por meio de um método científico universal e confiável para produzir conhecimento.

Logo, a educação científica pode auxiliar na formação de um cidadão contemporâneo desconstruindo a visão de ciência como produtora de verdades, certezas e fonte de conhecimento preciso. A contribuição da educação científica para formar um cidadão capaz de não ser subjugado pela sociedade contemporânea 
é de abordar os conteúdos de ciência, mas também sobre ciência, para que os estudantes sejam capazes de compreender e até fazerem parte do empreendimento científico. A ciência é uma das áreas que mais pode contribuir para uma escola útil para o século XXI, pois desconstruir a imagem mítica de ciência implica em desconstruir a própria ideia de verdades absolutas e certezas finais.

Outro ponto em que a educação científica pode contribuir para formar cidadãos do século XXI é na valorização da diversidade cultural. Ao apresentar o empreendimento científico, não como entidade isolada, mas como contribuindo e recebendo contribuição de outras tradições, percebe-se que todas as formas de conhecimento devem ser valorizadas, para o bem da própria ciência sob o risco de se fechar nela mesma e se tornar uma crença metafísica. Ainda, ao se desconstruir o mito da ciência isolada de outras tradições, entende-se que a própria ciência não é a única fonte de conhecimento confiável, e não cabe a ela, sozinha, as decisões que irão impactar em toda a sociedade. Desta forma, a educação científica pode propiciar um ambiente em que a ciência não é vista como um padrão de excelência a ser obedecido cegamente pela sociedade. Um cidadão educado a não ser subjugado por qualquer um que se coloca como autoridade tem o direito de valorizar outras formas de conhecimento, além da científica, para resolver seus problemas.

As inferências anteriores se referem ao que foi chamado de questão metafísica da educação: para que ensinar. Uma vez tendo sido desenvolvidas algumas considerações a respeito desta questão, a pesquisa relatada neste artigo se concentrou na questão de engenharia: como levar a educação científica pensada como útil para sala de aula, ou seja, quais aspectos os professores deveriam abordar para construir uma educação científica tal qual entendida como útil no século XXI?

A sugestão que foi implementada e avaliada, colhendo bons resultado, foi a de uma educação científica de e sobre ciência, por meio de um ensino subversivo visando uma aprendizagem significativa crítica. Defendeu-se, que tal abordagem poderia ser possível discutindo episódios históricos embebidos por considerações epistemológicas explícitas, a fim de desconstruir o entendimento de que há verdades e certezas incontestáveis. Ainda, que tais episódios necessitem de um aporte epistemológico para serem narrados e que a epistemologia de Feyerabend é não apenas coerente, mas complementar à proposta de um ensino subversivo para uma aprendizagem significativa crítica.

O objetivo geral da pesquisa, articular um aporte epistemológico da ciência com o ensino subversivo visando uma aprendizagem significativa crítica para abordar episódios históricos durante a formação de professores, parece ter sido alcançado. No entanto, tão importante quanto os avanços da pesquisa foram as novas questões que ela levantou. Tais conclusões implicam que a área de pesquisa em educação científica tem muitos desafios para serem encarados. Grande parte desses desafios não tem soluções simples, elas demandarão muitos anos de pesquisas e muitos profissionais que se dediquem a eles. Por fim, a educação científica tem enormes potencialidades ainda inexploradas para a formação de cidadãos para não serem subjugados no século XXI. 
Para que ensinar Ciência no Século XXI? - reflexões a partir da filosofia de

Feyerabend e do ensino subversivo para uma aprendizagem significativa crítica

\section{REFERÊNCIAS}

ARANHA, M. L. A. História da educação. 2a ed. São Paulo: Moderna, 1996.

ARTHURY, L. H. M. A cosmologia moderna à luz dos elementos da epistemologia de Lakatos. 133 f. Dissertação (Mestrado em Educação Científica e Tecnológica). Universidade Federal de Santa Catarina. Florianópolis, 2010.

AUSUBEL, D. P., NOVAK, J. D., HANESIAN, H. Psicologia educacional. Tradução Eva Nick. Rio de Janeiro: Interamericana, 1980.

DAMASIO, F.; PEDUZZI, L. O. Q. História e filosofia da ciência na educação científica: para quê? Revista Ensaio, v.19, p. 2583, 2017.

DAMASIO, F.; PEDUZZI, L. O. Q. O pior inimigo da ciência: procurando esclarecer questões polêmicas da epistemologia de Paul Feyerabend na formação de professores. Investigações em Ensino de Ciências, v. 20, n. 1, p. 97-126, 2015a.

DAMASIO, F.; PEDUZZI, L. O. Q. Considerações sobre a alcunha atribuída a Paul Feyerabend de "pior inimigo da ciência" e suas implicações para o ensino de ciências. Alexandria, v. 10, n. 1, p. 329-351, 2017b.

DAMASIO, F.; PEDUZZI, L. O. Q. Ciência: a nova religião? - possíveis implicações do debate para a educação científica. In: Encontro Estadual de Ensino de Física, VI, 2015, Porto Alegre, Anais... Porto Alegre: Instituto de Física, p. 48-57, 2015.

DAMASIO, F.; PEDUZZI, L. O. Q. Coerência e complementaridade entre a epistemologia de Paul Feyerabend e a teoria da aprendizagem significativa crítica. Investigações em Ensino de Ciências, v. 20 , n. 3, p. 61-83, 2015.

DAMASIO, F.; PEDUZZI, L. O. Q. A formação de professores para um ensino subversivo visando uma aprendizagem significativa crítica: uma proposta por meio de episódios históricos de ciência. Labore em Ensino de Ciências, v. 1, p. 14-34, 2016.

DAMASIO, F.; PEDUZZI, L. O. Q. A defesa do Copernicanismo teve papel central nas condenações de Galileu? A Física na Escola, v. 14, n.2, p. 14-26, 2016 b.

DAMASIO, F.; PEDUZZI, L. O. Q. Afinal, Einstein usou ou não dados experimentais para propor sua relatividade restrita? Com a palavra, ele mesmo. A Física na Escola, v. 15, n.1, p. 4-11, 2017 c.

DAMASIO, F.; PEDUZZI, L. O. Q. A formação continuada de professores para um ensino subversivo visando uma aprendizagem significativa crítica por meio de história e filosofia da ciência sob o viés relativista: um estudo de caso. Experiências em Ensino de Ciências, v.12, n.5, p. 47-67, 2017 d.

DUHEM, P. To save the phenomena, an essay on the idea of physics theory from Plato to Galileo. Chicago: University of Chicago Press, 1963.

ERICKSON, F. Qualitative methods in research on teaching. In: WITTROCK, M.C. (ed.), Handbook of research on teaching. New York: Macmillan, 1986.

FRONZA, K. R. K. Repercussões sociais decorrentes do avanço científico e tecnológico: manifestações curriculares resultantes da intervenção docente. 455 f. Tese (Doutorado em Educação Científica e Tecnológica). Universidade Federal de Santa Catarina, 2016. 
FEYERABEND, P. K. How to Defend Society against Science. Introductory Readings in the Philosophy of Science - 3rd Edition. KLEMKE, H. et.al. (ed.): p. 54-65, 1998.

FEYERABEND, P. K. Contra o método. São Paulo: Editora UNESP, 2007.

FEYERABEND, P. K. Adeus à razão. São Paulo: Editora UNESP, 2010.

FEYERABEND, P. K. A ciência para uma sociedade livre. São Paulo: Editora UNESP, 2011.

FEYNMAN, R. The character of physical law. Cambridge: MIT Press, 1967.

GOETZ, J. P. e LECOMPTE, M. D. Etnografia y diseño cualitativo em investigación educativa. Madrid: Ediciones Morata, 1988.

HOLTON, G. Einstein, Michelson, and the 'crucial' experiment. Isis, v. 60, n. 2, p. 132-197, 1969.

MOREIRA, M. A. A pesquisa em Educação em Ciências e a Formação Permanente do Professor de Ciências. Revista Chilena de Educación Científica, v. 3, n. 1, p. 10-17, 2004.

MOREIRA, M. A. Aprendizagem Significativa Crítica. Porto Alegre: Ed. do autor, 2005.

MOREIRA, M. A. Comportamentalismo, construtivismo e humanismo. Subsídios Teóricos para o Professor Pesquisador em Ensino de Ciências. Porto Alegre: IF-UFRGS, 2009.

MOREIRA, M. A. Unidades de enseñaza potencialmente significativos - UEPS. Aprendizagem Significativa em Revista, v. 1, n. 2, p. 43-63, 2011.

MOREIRA, M. A. Aprendizagem significativa em mapas conceituais. Textos de apoio ao professor de Física, v. 24, n. 3, 2013.

PENA, F. L. A. Por que, apesar do grande avanço da pesquisa acadêmica sobre ensino de Física no Brasil, ainda há pouca aplicação dos resultados em sala de aula? Revista Brasileira de Ensino de Física, v. 26, n. 4, p. 293-295, 2004.

POSTMAN, N.; WEINGARTNER, C. Contestação - nova fórmula de ensino. Rio de Janeiro: Editora Expressão e Cultura, 1978.

POSTMAN, N. Tecnopólio - a rendição da cultura à tecnologia. São Paulo: Nobel, 1994.

REDONDI, P. Galileu herético. São Paulo: Companhia das Letras, 1991.

STRAUSS, A.; CORBIN, J. Pesquisa qualitativa: técnicas e procedimentos para o desenvolvimento de teoria fundamentada. Porto Alegre: ARTMED, 2009.

THEOCHARIS, T.; PSIMOPOULOS, M. Where science has gone wrong. Nature, v. 329, n. 6140, p. 595-598, 1987.

Submetido em 19/06/2017

Aprovado em 05/02/2018

\section{Contato:}

Felipe Damasio

Avenida XV de Novembro, 61 Aeroporto

CEP 88.905-112 - Araranguá, SC - Brasil 